\title{
Voluntary assisted dying in the Australian state of Victoria: an overview of challenges for clinical implementation
}

\author{
Courtney Hempton ${ }^{1,2} \wedge$ \\ ${ }^{1}$ Alfred Deakin Institute for Citizenship and Globalisation, Deakin University, Waurn Ponds, Australia; ${ }^{2}$ Monash Bioethics Centre, Monash \\ University, Clayton, Australia \\ Correspondence to: Courtney Hempton. Alfred Deakin Institute for Citizenship and Globalisation, Deakin University, Waurn Ponds, Victoria, 3216, \\ Australia. Email: courtney.hempton@deakin.edu.au.
}

\begin{abstract}
On 19 June 2019 the Voluntary Assisted Dying Act 2017 (Vic) came into effect, making Victoria the first state in Australia to permit the practice of 'voluntary assisted dying'. As defined in the legislation, voluntary assisted dying refers to "the administration of a voluntary assisted dying substance and includes steps reasonably related to such administration", "for the purpose of causing a person's death". In essence, the model of voluntary assisted dying established in Victoria is designed for patients within the final weeks or months of life, who may receive medical-assistance to 'choose the manner and timing of their death'. The purpose of this paper is to overview the clinical implementation of voluntary assisted dying in Victoria, attending to three broad challenges: balancing tensions in policy goals and ensuring the legislated 'safeguards' function as intended, translating the complex legislation into clinical practice, and managing conscientious objection to voluntary assisted dying. While there is somewhat limited information available regarding the practice of voluntary assisted dying in Victoria, available data and anecdotal reports indicate the implementation of the state's complex model of voluntary assisted dying has not been without challenges, particularly in terms of balancing the legislated 'safeguards' and patient access to voluntary assisted dying, and translating aspects of the complex legislation into clinical practice. The release of more systematic voluntary assisted dying data by the state, alongside independent research into the operation of voluntary assisted dying, is necessary to better evaluate the implementation and impact of voluntary assisted dying as a new component of clinical practice.
\end{abstract}

Keywords: Conscientious refusal to treat; health legislation; euthanasia; active; voluntary; suicide; assisted; terminal care

Submitted May 22, 2020. Accepted for publication Feb 05, 2021.

doi: 10.21037/apm-20-1157

View this article at: http://dx.doi.org/10.21037/apm-20-1157

\section{Introduction}

In a historic transformation of health law, policy, and practice, Victoria is the first state in Australia to permit 'voluntary assisted dying' (VAD) $(1,2)$. The practice of VAD is regulated by the Voluntary Assisted Dying Act 2017 (Vic), which came into effect on 19 June 2019 (1). As defined in the legislation, VAD refers to "the administration of a
(VAD) substance and includes steps reasonably related to such administration", "for the purpose of causing a person's death" (1). In essence, VAD refers to a patient "choosing to take life-ending medication prescribed by a doctor" (3). As summarised by the state's Department of Health and Human Services, the enacted model of VAD "provides a safe legal framework for people who are suffering and dying

\footnotetext{
^ ORCID: 0000-0001-9444-1170.
} 
to choose the manner and timing of their death" (2). While the state is certainly not the first jurisdiction in the world to permit some form of medically-assisted death, the practice of VAD is distinctly regulated in Victoria.

This paper provides an overview of the initial clinical implementation of VAD in Victoria. Following a brief introduction to the establishment of the Voluntary Assisted Dying Act 2017 (Vic), the paper outlines the clinical implementation of aspects of the legislation in effect, specifically considering how tensions in policy goals are being navigated, and how the complex legislation is being translated into practice. To ensure references accurately reflect the model of VAD in effect, this overview draws primarily from literature and other documentation produced since the legislation passed in Victoria (i.e., since 29 November 2017), including qualitative and quantitative research, and data as reported on by the Voluntary Assisted Dying Review Board, in addition to drawing from media reports, particularly those featuring commentary from health practitioners and patients regarding the implementation of VAD (recognizing the limitations of these anecdotal reports). While a complete account of the law reform processes that eventuated in the legalization of VAD in Victoria is beyond the current scope, and variously detailed and analyzed elsewhere (4-9), where relevant, the paper also refers to key documents produced during the law reform process to provide additional context, particularly for explaining the policy-intent of the legislative provisions discussed.

It is important to note the establishment and practice of VAD in Victoria is not uncontested. However, debate regarding whether or not the state ought to have introduced VAD, and if so, what form this should or should not take, is beyond the purview of this paper. Rather, this overview focuses on the ways in which the enacted VAD legislation is being clinically implemented, considering the intent and scope of model legalized in Victoria. In this respect, the term 'voluntary assisted dying' is adopted (abbreviated to 'VAD'), as utilized in the Victorian legislation and associated documentation and literature, though with the acknowledgment that this term is itself contested, and that other terminology, including 'euthanasia', and 'assisted suicide', is also used to refer to the regime in effect in Victoria. The more generic term 'medically-assisted death' is used in this paper to refer broadly to the topic and practice of health and medical practitioners assisting patients to die, as variously construed in different jurisdictions.

\section{Overview of voluntary assisted dying in Victoria}

\section{The legalization of voluntary assisted dying}

The Voluntary Assisted Dying Act 2017 (Vic), came into effect on 19 June 2019 (1). The establishment of VAD in Victoria is the result of a parliamentary Inquiry into End of Life Choices that was convened to consider "the need for laws in Victoria to allow citizens to make informed decisions regarding their own end of life choices" $(10,11)$. Alongside a series of other recommendations pertaining to advance care planning and palliative care, the inter-party Legal and Social Issues Committee conducting the Inquiry recommended that the state introduce a model of 'assisted dying' $(12,13)$. Accepting the Committee's recommendation, the state government appointed a Ministerial Advisory Panel, to refine the initial 'assisted dying framework' proposed by the Committee (14-17), ultimately eventuating in the final legislation, which passed in late-November 2017.

Between the legislation passing and coming into effect in Victoria, there was an approximate 18-month period of time to enable preparation for the introduction of VADthe 'implementation period'- during which a complex VAD apparatus emerged. During the implementation period, a state-appointed 'Implementation Taskforce' (18-25) oversaw and contributed to the production of a vast array of guidelines and resources that shape the translation of the state's legislation into clinical practice in the Victorian context (3,26-30). Substantial, publicly-available resources include 'safety and quality guidance for health services' (31), 'model of care pathways for health services' (32), 'guidance for health practitioners' (26), and 'information for people considering voluntary assisted dying' (3), in addition to information, fact sheets, and training videos for health services (33-39) and health practitioners (27-30,40-44), and information for community members $(45,46)$, including an overview available in 'Easy English' and 17 community languages (47).

\section{The Victorian model of voluntary assisted dying}

As defined in the legislation, VAD refers to "the administration of a [VAD] substance and includes steps reasonably related to such administration", "for the purpose of causing a person's death" (1). The model of VAD established in Victoria is intended for patients within the final weeks or months of life- "only those who are already dying" (2). As specified in the legislation (1), to be 
eligible to access VAD, a patient must meet a number of stringently-assessed criteria. The patient must be diagnosed with a disease, illness, or medical condition that is assessed to be incurable, advanced, and progressive, and predicted to cause death within no more than six months, or no more than 12 months for those with a neurodegenerative diagnosis. The disease, illness, or medical condition must also be causing suffering that cannot be relieved in a way the patient themselves considers tolerable. The patient must be assessed to have decision-making capacity in relation to $\mathrm{VAD}$; in Victoria it is not possible to request access to VAD in an advance care directive (48). The patient must be aged 18 years or over, have lived in Victoria for at least one year before making a first request for VAD, and be an Australian citizen or permanent resident.

The model of VAD primarily provides for a practice of what is termed 'self-administration', which allows a patient to self-administer a prescribed substance (e.g., oral liquid) with the intention of causing their own death; only if a patient is assessed to be physically unable to self-administer the substance is 'practitioner administration' permitted, which allows a medical practitioner to directly administer the substance to cause death, in a way deemed most appropriate for that particular patient (1).

The legislation details an extensive request and assessment process for a patient to request access to VAD. The process of assessment necessitates the involvement of at least two eligible medical practitioners (either or both may refer the patient to an additional specialist to clinically assess aspects of eligibility as deemed necessary), referred to as the 'coordinating' and 'consulting' practitioners. Not all medical practitioners are eligible to be a coordinating or consulting practitioner; to be eligible to act in these roles for a given patient, each medical practitioner must hold a fellowship with a specialist medical college or be a vocationally registered general practitioner $(1,26)$, and each must complete and pass mandatory training $(28,29)$. While details of the training content are not publicly available, in general the training ensures medical practitioners understand their roles and requirements as detailed in the legislation. Notably, nurse practitioners are not eligible to participate as either the coordinating or consulting practitioner in Victoria; only medical practitioners with the requisite experience and training are eligible.

Victoria has not established a 'right' to VAD—-there is "no universal access, and people cannot demand (VAD)" (49). Rather, a patient's "access to (VAD) will depend on the availability of participating health services and medical practitioners, and the approval of the state" (49). As such, a key logistical component of navigating the tension between safeguards and access to VAD is the availability of health services and medical practitioners willing to participate in providing VAD-related services and care.

\section{The clinical implementation of voluntary assisted dying}

While in essence VAD broadly aligns with regimes of medically-assisted death enacted in other jurisdictions, the model of VAD adopted in Victoria is distinctly regulated. White, Willmott, and Close identified a series of challenges for implementing the Victorian model of VAD (50). This paper traces the ways in which these foreseeably clinically-challenging aspects of the legislation have been implemented. White, Willmott, and Close outlined three broad challenges for the clinical implementation of VAD in Victoria: balancing tensions in policy goals and ensuring the legislated 'safeguards' function as intended, translating the complex legislation into clinical practice, and managing conscientious objection to VAD (50). While it may be somewhat too soon to determine whether or not the clinical implementation of VAD has been successful-or more fundamentally, even by what metric such a determination ought to be made-it is no less essential to consider the challenges of clinically-implementing the model of VAD adopted in Victoria, including challenges foreseen prior to, and after the law came into effect.

\section{Navigating tensions in policy goals}

The Victorian model of VAD has been described repeatedly by members of the state government as "the safest and most conservative in the world" $(51,52)$. In making this claim, the government is presumably implicitly referencing the totality of 'safeguards' embedded in the Victorian legislation. As delineated by the Ministerial Advisory Panel, the VAD legislation features '68 safeguards' [calculated per the then proposed Voluntary Assisted Dying Bill 2017 (Vic) (53)], across a range of aspects of the practice, as compared to models of medically-assisted death enacted in other jurisdictions, including Canada, Belgium, the Netherlands, and a number of US states. Features of the legislation counted as 'safeguards' include patient eligibility and access criteria, the request, assessment, and administration process, medication management and storage requirements, protections for health practitioners, and mandatory reporting and oversight 
mechanisms, in addition to the creation of new offences, such as inducing another person to request VAD, and falsifying records (16). The safeguards were variously designed to protect members of the community and health practitioners in relation to $\mathrm{VAD}$, resulting in a "rigorous and prescriptive VAD process aiming to attract political support for a conservative model" (50).

The legislative complexity of the "safest and most conservative' model of medically-assisted death in the world presents a challenge for clinical implementation. Ahead of the legislation coming into effect, White, Willmott, and Close, contended that "the principal implementation challenge is ensuring that this complexity functions protectively, as intended, and does not unfairly prevent eligible people from accessing VAD" (50). In considering the tension between these goals, McDougall and Pratt comprehensively examined the "discourse of safety" (54) in relation to the VAD legislation, alongside the underlying premise that "access to VAD for eligible patients is both a goal of policymakers and a community expectation" (54). Analyzing the ethical relationship between the legislated 'safety' provisions and 'equal access' to VAD (in terms of horizontal equity, patient agency, high quality of care, and supportive social norms), McDougall and Pratt conclude that, "while safety is undoubtedly ethically important... a legislative focus on maximizing safety comes at the expense of equal access" (54). There is a potential chasm between the legislated safeguards, and the perceived obligation or expectation that health services, perhaps particularly those that are state-funded, provide patients with access to options that are lawfully permissible. Navigating the tension between the 'safeguards' and 'access' to VAD is thus a pivotal challenge for clinical implementation.

A logistical component of navigating this tension between safeguards and access to VAD is the availability of health practitioners willing to participate in providing VAD-related services and care, in particular eligible medical practitioners potentially willing to act as either a coordinating or consulting practitioner. However, while patient access to VAD is wholly contingent on the participation of senior and specifically-trained medical practitioners, there is still limited systematic data available regarding the willingness of these practitioners to participate in the practice of VAD as legislated in Victoria. In the broadest sense, VAD legislation is being 'clinically implemented', in a context in which there is limited information about the willingness of either health services or health practitioners to participate. To be clear, there is absolutely no requirement for health services to participate in providing VAD; all health services are able to determine whether or not to provide VAD, and the extent of their involvement, including whether or not to facilitate access to VAD through referral to another health service (32-34). While a number of health services conducted internal workforce surveys during the 'implementation period' regarding the particular service's capacity to provide various levels of access to VAD [as suggested by the state government to aid in determining the appropriate VAD 'model of care pathway' (33)], such information is generally not available publicly.

However, emerging empirical evidence further supports the assertion that the lauded 'safeguards' in the Victorian model of VAD may be functioning in practice as impediments to patient access to VAD (considering patients prima facie eligible). In particular, two surveys conducted during the implementation period provide some insight into the attitudes of health practitioners in relation to the legalization and practice of VAD, considering the specific legislation as passed; a multi-site mixed-methods anonymous online survey was conducted across seven public health services in Victoria, including six metropolitan services (five tertiary-level), and one regional service $(\mathrm{n}=5,159)(55)$, and a similar survey was conducted at a regional health service $(n=1,624)$. Both of these surveys indicated high levels of support for the legalization of VAD [73\% (Sellars, Tacey, McDougall et al., unpublished data); 87.6\% (Fuscaldo, Gwini, Larsen, et al., (56))].

Notably however, each survey also demonstrated that support for the legalization of VAD in Victoria was comparatively lower amongst medical specialists with responsibilities for caring for patients at the end of life (e.g., palliative care physicians and geriatricians), and amongst medical specialists with responsibilities for caring for other patients most likely to be eligible and potentially request access to VAD (i.e., patients diagnosed with cancers, or advanced cardiac, neurological, or respiratory diseases, illnesses, or conditions) [Fuscaldo, Gwini, Larsen et al., (56), Sellars, Tacey, McDougall et al. manuscript under review]. As summarized by McDougall and Pratt, the limited number of eligible medical practitioners willing to participate in providing VAD services, in particular to act as either the coordinating or consulting medical practitioner, is reported as a key barrier to patient access to VAD (54).

However, it is necessary to somehow navigate this inherent tension in the legislation, in order to simultaneously advance these potentially conflicting policy aims of 'safety' and access. White, Willmott, and Close 
suggest "system design is the key so that complexity is 'internally facing' and not experienced by people seeking VAD and doctors assisting them" (50). The state-funded VAD 'Care Navigator' service established in Victoria may also offer a somewhat 'internally-facing' and centralized approach, in particular to balance the tension between maintaining 'safeguards' for practitioners (i.e., to protect their right not to participate in any way) and patient access to VAD. Indeed, in the published information for people considering VAD', patients are referred to the Care Navigator service $(3,54)$; McDougall and Pratt highlight that this information for patients "repeatedly presents the VAD care navigators as enabling access when a patient's doctor is not participating or referring" (54). However, as widely reported by media in the days after the legislation came into effect, the intended 'state-wide' service to be provided by the care navigators is curtailed by the federal Criminal Code 1995 (Ctb). The federal legislation prohibits "using a carriage service for suicide-related material" (57), in effect, making use of the phone or internet to discuss VAD potentially legally problematic, so all consultations need to occur in-person $(58,59)$ - an obvious challenge for the initial two care navigators to effectively service the entire state. Thus, while the care navigators may assist navigate the tension between protecting practitioners and facilitating patient access to VAD, McDougall and Pratt note it is "unclear whether navigators will be effective at facilitating access and whether they will be able to do so equitably" (54).

The most systematic data currently available regarding the implementation of VAD across the state has been reported by the independent 'Voluntary Assisted Dying Review Board', which is tasked with oversight of VAD in Victoria $(60,61)$. As relevant to the potential (in)availability of trained medical practitioners, the Review Board reported that (during the initial period of operation, 19 June to 31 December 2019), 365 medical practitioners had 'registered' for the mandatory training (taking an average of four hours to complete). Of these, 134 had then registered for the 'voluntary assisted dying portal', as necessary to submit the required VAD documentation [assessment forms, permit applications etc. (1)]. The Review Board reported 33\% of trained medical practitioners were located outside the metropolitan Melbourne area (i.e., located in regional or rural Victoria) (61). While the Review Board reported that some patients "have found it difficult to find a medical practitioner who has undertaken the training and is willing to participate" (61), the Review Board "expects access to trained medical practitioners will become easier in time" (61).

Commenting on the release of the Review Board's report, Victorian Minister for Health Jenny Mikakos tweeted that the report indicates the legislation "is working well and as intended". However, the Review Board's report did not provide any information about patients requesting access to VAD prior to the first formal assessment, meaning there is no systematic data available regarding patients who may have wanted to access VAD and been unable to, or the reasons why this may have been the case (62). Additionally, no further information was reported about the characteristics of the medical practitioners completing training, and how this may impact patient access to VAD. As such, the limited data reported by the Review Board must be interpreted with caution, particularly in terms of understanding health and medical practitioner participation in aspects of VAD-related service provision, and patient access (and potential in-access) to VAD across the state (62).

Anecdotally, a number of media reports indicate that (prima facie) eligible patients are experiencing challenges sourcing a suitably qualified medical practitioner willing to act as either the coordinating or consulting practitioner; there is no publicly available list of medical practitioners who have completed the necessary training and may be willing to assess patients for VAD (noting some practitioners who have completed the training may not have intention to participate). The impact of the "bureaucratic roadblocks" (63) identified in media reports include barriers to accessing health practitioners who are eligible, willing, and trained to participate. In particular, reports highlight challenges related to navigating access to VAD, either locally or within a reasonable timeframe, including reports of challenges accessing particular specialists, particularly in regional and rural areas (64), and additional administrative challenges, such as demonstrating residency requirements. As commented on by a Victorian general practitioner, "the strict interpretation of the legislation means people who were never meant to be excluded from the scheme are being effectively locked out" (65).

\section{Translating legislation into practice}

As already somewhat evidenced, translating the state's complex VAD legislation into clinical practice was a foreseeable implementation challenge. While the legislation renders the administration of VAD in terms of legal standards, an essential implementation task was-and continues to be-the effective translation of these standards 
into clinical care. As noted by White, Willmott, and Close, "the VAD legislation mandates detailed intervention into clinical practice-indeed, it arguably creates a new area of clinical practice" (50). However, there is still limited systematic information regarding how VAD is being integrated into clinical practice across Victoria, and the potential implications of the ways in which the legislation is being translated in clinical terms.

By way of example, one particularly notable feature of the VAD legislation that presents a distinct challenge for clinical implementation is a section that prohibits all health practitioners from initiating a discussion about VAD with their patients-referred to by Moore, Kendal, and Hempton as a "gag clause" (66-68). As specified in the legislation, a registered health practitioner who provides health or professional care services must not, in the course of providing such services, either "(a) initiate discussion with that person that is in substance about VAD; or (b) in substance, suggest VAD to that person" (1). As clarified in an explanatory memorandum, this prohibition extends to the provision of written information (69), such as providing a patient with written materials about VAD (70). This kind of gag clause is notably unprecedented in Victoria, and a number of ethical, legal, and clinical experts have commented that, to their knowledge, there is no other legislation in effect in the state that similarly prohibits a health or medical practitioner, guided by their professional judgement, from introducing a lawful clinical option for a patient to consider $(66,70,71)$. In justifying the introduction of this unprecedented prohibition, the Ministerial Advisory Panel stated its intent was "to ensure a person is not coerced or unduly influenced into accessing VAD and to demonstrate the request for VAD is the person's own voluntary decision" (16).

In effect, this legislated gag clause presents particular challenges for clinical practice. A number of authors have commented on implications of the prohibition, including the impact on honest and open communication between health practitioners and their patients, and potential negative impact on the therapeutic relationship $(66,70,71)$. Qualitative survey data also indicates that health practitioners identified the gag clause as potentially creating challenges in practice, and complicating existing 'end of life' care. From the results of one of the aforementioned mixed-methods surveys about VAD conducted during the 'implementation period', McDougall, Hayes, Sellars and colleagues thematically analyzed the challenges health practitioners anticipated in association with the (forthcoming) legislative change. As relevant to the translation of the 'gag clause' into practice, concern was expressed that health and medical practitioners may "avoid end-oflife care discussions because of the increased complexity that the availability of VAD creates, for example being misinterpreted as having initiated a VAD discussion” (55). The authors note a comment by a 'senior doctor', who selfidentified as 'unsure' regarding the legalization of VAD:

"Fear that junior and senior doctors will lose confidence in listening to and exploring patients' distress close to the end of life for fear that either the patient will raise VAD which they will find uncomfortable, difficult and time consuming, or that they will be misinterpreted as having 'initiated' conversations re VAD” (55).

This study also indicates that health practitioners anticipated that the translation of VAD legislation into clinical practice would be challenging in a variety of other ways. From a sub-set of qualitative data, the authors identified a range of challenges (similar across the two health services analyzed), that "included various types of burdens for staff, issues around organizational culture, the logistics of delivering VAD under the specific Victorian law and the relationship of VAD to the rest of the hospital's work overall" (55). This study indicated that "challenges associated with VAD were anticipated across all clinical roles in the hospital and for both objectors and supporters of VAD" (55). Most notably, this study identified that, in addition to health practitioners anticipating individual-level challenges due to potential increased conflict, workload, and emotional burden, health practitioners also anticipated health system-level challenges, including 'delivering VAD' (e.g., logistics, skill base, equity of access) and 'VAD within the hospital' (e.g., confusion between VAD and other aspects of clinical care, avoidance of 'end of life' discussions, decreased trust, and resourcing) (55).

White, Willmott, and Close suggest supporting the translation of voluntary assisted legislation into practice through establishing "a clinical network with expertise in facilitating and educating about VAD" (50). While it is unclear how such clinical networks are operating in Victoria-either formally or informally-the Voluntary Assisted Dying Review Board reported that 'specialist communities of practice' are accessible as relevant, with aim to "share experiences, lessons and provide peer support" (61). Notably, there are two separate communities of practice, one for "medical practitioners who have undertaken (VAD) training", and one for "health service staff involved in (VAD) as part of their roles" (61). 
At this stage, it is not systematically clear which of these anticipated implementation challenges were particularly problematic in practice, at either an individual or healthsystem level-research conducted since the legislation has been operational will make a valuable contribution to further understanding the attitudes and behaviors of health and medical practitioners, including whether the anticipated challenges of implementing VAD in clinical practice eventuated, whether unanticipated challenges were encountered, and how these were managed in practice. As concluded by McDougall, Hayes, Sellars and colleagues, it is "important to continue to research clinicians' experiences to understand whether and how these anticipated challenges evolve in practice" (55). Overall though, it is challenging to evaluate whether or not the VAD legislation is being effectively clinically implemented. As noted by McDougall and Pratt, "meaningfully assessing whether patients have access to high quality VAD care will not be possible until indicators and criteria beyond compliance with the legislated administrative process have been formulated" (54).

\section{Managing conscientious objection}

In Victoria, the participation of health practitioners in any aspect of VAD service provision is absolutely discretionary; 'conscientious objection' in relation to VAD is a right. As outlined in the legislation, any registered health practitioner with a 'conscientious objection' to VAD has the right to refuse to support or participate in any aspect of care related to $\mathrm{VAD}$, including the provision of information, participation in the request and assessment process, including applying for a permit, supplying, prescribing, dispensing, or administering the VAD substance, or being present at the time of such administration (1). Notably, this new right does not confer any obligations on health practitioners, for example requiring the provision of basic information or referral to another health practitioner [(50,54), Hempton, manuscript under review]. In effect, health practitioners have more rights than patients in relation to VAD in Victoria- "there are no new rights for patients established by the legislation, while health practitioners have the right to "conscientiously object" (Hempton, manuscript under review).

Managing an unfettered right to 'conscientious objection' as legislatively constituted was a foreseeable challenge for clinical implementation. As noted by White, Willmott, and Close, "the legal right to conscientiously object is clearly stated... but the VAD law does not establish a framework for respecting conscience. This will need to be decided in the implementation process" (50). While the scope of conscientious objection is delineated in the legislation, the meaning of 'conscientious objection' is not defined. The legislation draws no distinction between conscientious and 'non-conscientious' objection to VAD, the lack of definitional clarity presents a challenge for the clinical implementation of VAD, particularly in terms of balancing respect for 'conscience', while also facilitating patient access to $\operatorname{VAD}(50)$.

Further, the notion of 'conscientious objection' operates not only at the level of individual practitioners, but also at the level of institutions. While not explicit in the legislation, as previously mentioned there is no obligation for health services to provide VAD services in Victoria, and patient access to VAD is contingent on the participation of health services, including hospitals, community health, primary care, residential aged care, and other organizations that may provide care to patients wanting to access VAD. The Department of Health and Human services in collaboration with the Victorian Healthcare Association outlined three VAD 'model of care pathways', distinguishing the level of VAD service provision within the health service. A health service providing 'single service' access (Pathway A) is able to provide comprehensive access to VAD within the health service, while those providing 'partnership service' access (Pathway B) may be able to provide access to some aspects of VAD though require additional external resources, for example referral to a specialist medical practitioner. A health service which identifies it is unable to provide access in either a single or partnership capacity, for example due to lack of eligible or willing health practitioners to participate, may act as an 'information and support service' (Pathway C) (32).

Regardless of the model of care pathway adopted, all health services are encouraged to educate health practitioners and other staff regarding VAD as a lawful health service, including providing information about the health service's position on VAD and associated policy, internal referral and decision-making processes, and the legal responsibilities of health practitioners in relation to VAD (34). Health and aged care service providers are further advised to consider how VAD may be incorporated into existing aged care (37) and 'end of life care' service provision as relevant, including access to psychological support, social work, and spiritual care, palliative care and specialist palliative care, and advance care planning (36). In particular, health services adopting 'Pathway $\mathrm{C}$ ' are encouraged to produce policy guidelines to support health 
practitioners and other staff to provide information and support to patients who request information about or access to VAD—such as referral to another health service or general practitioner-though "individual health services are responsible for determining their response to referrals related to VAD" (35).

Health services may also elect not to participate in any aspect of $\mathrm{VAD}$, including information provision, as in alignment with "the values of the health service" (34). In particular, a number of faith-based health service providers have chosen not to provide information about or facilitate access to VAD. For example, in response to the passing of the legislation in Victoria, Catholic Health Australia, the largest non-government conglomerate of health, community, and aged care services in the country, established a 'taskforce' to respond to $\operatorname{VAD}(72,73)$. In a media statement in response to the introduction of VAD in Victoria, Catholic Health Australia declared it "will neither provide nor facilitate" (74) VAD, describing its position as being in accordance with the Hippocratic tradition of medicine, and consistent with the positions of the Australian Medical Association (75) and the World Medical Association (76,77). The statement was endorsed by a number of Catholic Health Australia member organisations providing health and aged care services in Victoria, notably including a number offering specialist palliative care services (74).

If a health service chooses not to provide any VAD services, the Department of Health and Human Services advises that the health service should determine how it will respond to patient requests for information about or access to VAD, including support for health practitioners and other staff who will be confronted with these conversations. It is suggested "the health service should inform the patient as soon as practicable that they will not assist them" (34) with information about or access to VAD, though it is clear the health service has "no obligation to refer the patient to someone who will assist them, but should not inhibit a person's access" (34).

\section{Conclusions}

The introduction of VAD in the Australian state of Victoria is a historic transformation in health law, policy, and practice. Translating the state's complex VAD legislation into clinical practice was a foreseeable implementation challenge. This paper provided an overview of the clinical implementation of VAD in Victoria, including how tensions in policy goals are being navigated, how the complex legislation is being translated into practice, and how conscientious objection is being managed. While there is somewhat limited information available regarding the practice of VAD in Victoria to date, particularly from the perspectives of patients and their families and carers, available data and anecdotal reports indicate the implementation of the complex model of VAD has not been without challenges, particularly in terms of balancing the legislated 'safeguards' and patient access to VAD. The release of more systematic VAD data by the state, alongside independent research into the operation of VAD, is necessary to more comprehensively evaluate the implementation and impact of VAD as a new component of clinical practice. More essentially, however, meaningful assessment of the clinical implementation of VAD may require the specification of indicators-beyond simple legislative compliance—of what, indeed, high quality VAD care entails.

\section{Acknowledgments}

Parts of this paper draw on my doctoral research, and I extend appreciation to my supervisors, Catherine Mills and Justin Oakley, for ongoing discussions that improved aspects of this broader work in progress. My gratitude also to a number of academics and clinicians who generously shared advance copies of manuscripts under review (held on file). I am extremely grateful to Jess Young for her ongoing and generous collegiality, and to the editors Nancy Preston and Sheri Mila Gerson, for inviting me to contribute to this special issue on Hastened Death-much appreciation.

Funding: None.

\section{Footnote}

Conflicts of Interest: The author has completed the ICMJE uniform disclosure form (available at http://dx.doi. org/10.21037/apm-20-1157). The series "Hastened Death" was commissioned by the editorial office without any funding or sponsorship. Ms. Hempton reports other from Australian Government and Australian Research Council, during the conduct of the study; and was previously affiliated with the Monash Health Voluntary Assisted Dying Working Group and Voluntary Assisted Dying Steering Committee; views are her own. The author has no other conflicts of interest to declare. 
Provenance and Peer Review: This article was commissioned by the Guest Editors (Nancy Preston, Sheri Mila Gerson) for the series "Hastened Death" published in Annals of Palliative Medicine. The article has undergone external peer review.

Ethical Statement: I am accountable for all aspects of the work in ensuring that questions related to the accuracy or integrity of any part of the work are appropriately investigated and resolved.

Open Access Statement: This is an Open Access article distributed in accordance with the Creative Commons Attribution-NonCommercial-NoDerivs 4.0 International License (CC BY-NC-ND 4.0), which permits the noncommercial replication and distribution of the article with the strict proviso that no changes or edits are made and the original work is properly cited (including links to both the formal publication through the relevant DOI and the license). See: https://creativecommons.org/licenses/by-nc-nd/4.0/.

\section{References}

1. Voluntary Assisted Dying Act 2017 (Vic) (Austl).

2. State of Victoria Department of Health and Human Services. Voluntary assisted dying: Overview. Available online: health.vic.gov.au/hospitals-and-health-services/ patient-care/end-of-life-care/voluntary-assisted-dying/ vad-overview. Accessed 24 February 2019.

3. State of Victoria Department of Health and Human Services. Voluntary assisted dying: Information for people considering voluntary assisted dying. In: Services $\mathrm{DoHaH}$, editor. Melbourne: Victorian Government, 2019.

4. Duckett S. Pathos, death talk and palliative care in the assisted dying debate in Victoria, Australia. Mortality 2019;25:1-16.

5. Keown J. 'Voluntary assisted dying' in Australia: The Victorian parliamentary committee's tenuous case for legalization. Issues Law Med 2018;33:55-81.

6. Mendelson D. Voluntary assisted dying legislation in Victoria: What can we learn from The Netherlands experience? J Law Med 2017;25:30-45.

7. Rutherford J. The role of the medical profession in Victorian assisted dying law reform. J Law Med 2018;26:246-64.

8. White B, Willmott L. Evidence-based law making on voluntary assisted dying. Aust Health Rev 2020;44:544-6.

9. Hempton C, Mills C. Constitution of 'the already dying':
The emergence of voluntary assisted dying in Victoria. Journal of Bioethical Inquiry Forthcoming.

10. Parliament of Victoria Legislative Council Standing Committee on Legal and Social Issues. Community views sought on choices for end of life, 2015.

11. Parliament of Victoria. Inquiry into End of Life Choices. 2016. Available online: parliament.vic. gov-au/402-lsic-lc/inquiry-into-end-of-life-choices. Accessed 24 February 2019.

12. Parliament of Victoria Legislative Council Standing Committee on Legal and Social Issues. Inquiry into end of life choices: Interim report. Parliament of Victoria; 2015.

13. Parliament of Victoria Legislative Council Standing Committee on Legal and Social Issues. Inquiry into end of life choices: Final report. Parliament of Victoria; 2016.

14. State of Victoria Department of Health and Human Services. Voluntary Assisted Dying Bill: Discussion paper. Melbourne: Victorian Government; 2017.

15. State of Victoria Department of Health and Human Services. Voluntary Assisted Dying Bill: Interim report of the Ministerial Advisory Panel—consultation overview. In: Services DoHaH, editor. Melbourne: Victorian Government, 2017.

16. State of Victoria Department of Health and Human Services. Ministerial Advisory Panel on Voluntary Assisted Dying: Final report. Melbourne: Victorian Government, 2017.

17. O'Connor MM, Hunt RW, Gardner J, et al. Documenting the process of developing the Victorian voluntary assisted dying legislation. Aust Health Rev 2018;42:621-6.

18. State of Victoria Department of Health and Human Services. Voluntary Assisted Dying Implementation Conference. Available online: health.vic.gov.au/hospitalsand-health-services/patient-care/end-of-life-care/ voluntary-assisted-dying/implementation-conference. Accessed 24 February 2019.

19. Hunter P. Voluntary assisted dying: A Victorian clinical perspective. Voluntary Assisted Dying Implementation Conference; 8 May 2019; Melbourne, Victoria, Australia, 2019.

20. Mewett G. Voluntary assisted dying and palliative care: How can they co-exist? Voluntary Assisted Dying Implementation Conference; 8 May 2019; Melbourne, Victoria, Australia, 2019.

21. Mewett G. Voluntary assisted dying and the general practitioner. Voluntary Assisted Dying Implementation Conference; 9 May 2019; Melbourne, Victoria, Australia, 2019. 
22. O'Kane C, Cordery N. Voluntary assisted dying: Aged and community care services. Voluntary Assisted Dying Implementation Conference; 9 May 2019; Melbourne, Victoria, Australia, 2019.

23. Detering K. Implementation of voluntary assisted dying at Austin Health. Voluntary Assisted Dying Implementation Conference; 9 May 2019; Melbourne, Victoria, Australia, 2019.

24. Adams M. Implementation of the VAD legislation at Bendigo Health. Voluntary Assisted Dying Implementation Conference; 9 May 2019; Melbourne, Victoria, Australia, 2019.

25. Catford J. Voluntary assisted dying: How is Epworth responding? Voluntary Assisted Dying Implementation Conference; 9 May 2019; Melbourne, Victoria, Australia, 2019.

26. State of Victoria Department of Health and Human Services. Voluntary assisted dying: Guidance for health practitioners. In: Services DoHaH, editor. Melbourne: Victorian Government, 2019.

27. State of Victoria Department of Health and Human Services. Voluntary assisted dying: Quick reference guide for health practitioners. In: Services DoHaH, editor. Melbourne: Victorian Government, 2019.

28. State of Victoria Department of Health and Human Services. Medical practitioners wanting to participate in voluntary assisted dying [factsheet]. In: Services DoHaH, editor. Melbourne: Victorian Government, 2019.

29. State of Victoria Department of Health and Human Services. Co-ordinating and consulting medical practitioner information. Available online: health.vic.gov.au/hospitalsand-health-services/patient-care/end-of-life-care/ voluntary-assisted-dying/coordinating-consulting-medicalpractitioner-information. Accessed 24 February 2019.

30. State of Victoria Department of Health and Human Services. Voluntary assisted dying: Information for nurses and allied health practitioners. In: Services DoHaH, editor. Melbourne: Victorian Government, 2019.

31. State of Victoria Department of Health and Human Services, Victorian Healthcare Association. Voluntary assisted dying safety and quality guidance for health services. In: Services DoHaH, editor. Melbourne: Victorian Government, 2019.

32. State of Victoria Department of Health and Human Services, Victorian Healthcare Association. Voluntary assisted dying model of care pathways for health services. In: Services DoHaH, editor. Melbourne: Victorian Government, 2019.
33. State of Victoria Department of Health and Human Services, Victorian Healthcare Association. Voluntary Assisted Dying Act 2017: Preparing for voluntary assisted dying. In: Services DoHaH, editor. Melbourne: Victorian Government, 2019.

34. State of Victoria Department of Health and Human Services. Health service participation in voluntary assisted dying [factsheet]. In: Services DoHaH, editor. Melbourne: Victorian Government, 2018.

35. State of Victoria Department of Health and Human Services. Health service policy guidance for voluntary assisted dying [factsheet]. In: Services DoHaH, editor. Melbourne: Victorian Government, 2019.

36. State of Victoria Department of Health and Human Services. Voluntary assisted dying considerations in endof-life care [factsheet]. In: Services DoHaH, editor. Melbourne: Victorian Government, 2019.

37. State of Victoria Department of Health and Human Services. Voluntary assisted dying guidance for aged care providers [factsheet]. In: Services DoHaH, editor. Melbourne: Victorian Government, 2019.

38. State of Victoria Department of Health and Human Services. The statewide Voluntary Assisted Dying Care Navigator Service [factsheet]. In: Services DoHaH, editor. Melbourne: Victorian Government, 2019.

39. State of Victoria Department of Health and Human Services. Voluntary assisted dying in Victoria: The role of interpreters [factsheet]. In: Services DoHaH, editor. Melbourne: Victorian Government, 2019.

40. State of Victoria Department of Health and Human Services. Supporting patients who are not eligible for voluntary assisted dying [factsheet]. In: Services DoHaH, editor. Melbourne: Victorian Government, 2019.

41. State of Victoria Department of Health and Human Services. Voluntary assisted dying: Initial discussions about voluntary assisted dying [training video]. In: Services DoHaH, editor. Melbourne: Victorian Government, 2019.

42. State of Victoria Department of Health and Human Services. Voluntary assisted dying: Decision making capacity [training video]. In: Services $\mathrm{DoHaH}$, editor. Melbourne: Victorian Government, 2019.

43. State of Victoria Department of Health and Human Services. Voluntary assisted dying: Identifying coercion [training video]. In: Services DoHaH, editor. Melbourne: Victorian Government, 2019.

44. State of Victoria Department of Health and Human Services. Voluntary assisted dying: Discussing the ineligibility [training video]. In: Services DoHaH, editor. 
Melbourne: Victorian Government, 2019.

45. State of Victoria Department of Health and Human Services. Voluntary assisted dying: After death occurs [factsheet]. Victorian Government, Melbourne. 2019. Available online: health.vic.gov.au/about/publications/ policiesandguidelines/information-for-people-consideringvoluntary-assisted-dying. Accessed 25 August 2019.

46. State of Victoria Department of Health and Human Services. Community information about voluntary assisted dying. In: Services DoHaH, editor. Melbourne: Victorian Government, 2019.

47. Health Translations. Voluntary assisted dying. 2018. Available online: healthtranslations.vic.gov.au/bhcv2/ bhcht.nsf/PresentDetail?open\&s=Voluntary_assisted_ dying. Accessed 1 December 2020.

48. Hempton C, Bhatia N. Deciding for when you can't decide: The Medical Treatment Planning and Decisions Act 2016 (Vic). J Bioeth Inq 2020;17:109-20.

49. Hempton C. Voluntary assisted dying will soon be legal in Victoria, and this is what you need to know. The Conversation 2019.

50. White BP, Willmott L, Close E. Victoria's voluntary assisted dying law: clinical implementation as the next challenge. Med J Aust 2019;210:207-9.e1.

51. Premier of Victoria. Debate of historic voluntary assisted dying bill starts, 2017.

52. Premier of Victoria. A genuine, compassionate choice for Victorians, 2019.

53. Voluntary Assisted Dying Bill 2017 (Vic) (Austl.).

54. McDougall R, Pratt B. Too much safety? Safeguards and equal access in the context of voluntary assisted dying legislation. BMC Med Ethics 2020;21:38.

55. McDougall R, Hayes B, Sellars M, et al. 'This is uncharted water for all of us': challenges anticipated by hospital clinicians when voluntary assisted dying becomes legal in Victoria. Aust Health Rev 2020;44:399-404.

56. Fuscaldo G, Gwini SM, Larsen R, et al. Do health service staff support the implementation of voluntary assisted dying at their workplace? Internal Medicine Journal. doi. org/10.1111/imj.15285

57. Criminal Code Act 1995 (Cth) (Austl.).

58. Cunningham M. Doctors, family warned they could be breaking law discussing euthanasia on phone, internet. The Age 2019.

59. Martin L. Assisted dying: Doctors given updated legal advice over risk of breaching federal laws. The Guardian 2019.

60. Voluntary Assisted Dying Review Board. Report of operations: 2018-2019. In: Victoria SC, editor. Mel- bourne: Victorian Government, 2019.

61. Voluntary Assisted Dying Review Board. Report of operations: June to December 2019. In: Victoria SC, editor. Melbourne: Victorian Government, 2020.

62. Hempton C, Trabsky M. Without more detail, it's premature to say voluntary assisted dying laws in Vic-toria are 'working well'. The Conversation 2020.

63. Silva K. Voluntary euthanasia patients in Victoria caught in red-tape bottleneck. ABC News 2019.

64. Cunningham $M$. Terminally ill die locked out of euthanasia laws as doctors warn of specialist shortage. The Age 2020.

65. Cunningham M. Patients 'too tired, unwell' to clear assisted dying's red tape hurdle. The Age 2019.

66. Moore B, Hempton C, Kendal E. Victoria's voluntary assisted dying Act: Navigating the 'section 8' gag clause. Med J Aust 2020;212:67-68.e1.

67. Cunningham $M$. Law restricting doctors from initiating euthanasia talk is 'gag clause', academics say. The Age 2020.

68. Kirby T. Gag clause prevents discussion of assisted dying in Victoria, Australia. Lancet Respir Med 2020;8:341-2.

69. Voluntary Assisted Dying Bill 2017 (Vic) (Austl.)_ Explanatory Memorandum.

70. Johnston C, Cameron J. Discussing voluntary assisted dying. J Law Med 2018;26:454-63.

71. Willmott L, White B, Ko D, et al. Restricting conversations about voluntary assisted dying: Implications for clinical practice. BMJ Support Palliat Care 2020;10:105-10.

72. Catholic Health Australia. CHA VAD Response Taskforce: Clinical governance recommendations. Braddon: Catholic Health Australia, 2019.

73. Fleming DJ. An enduring ethic of end of life care: Catholic Health Australia's response to Victoria's 'voluntary assisted dying' act as participatory theological bioethics. Australas Cathol Rec 2019;96:458-72.

74. Catholic Health Australia. Catholic health and aged care services response to the 'Voluntary Assisted Dying Act', 2019.

75. Australian Medical Association. AMA position statement: Euthanasia and physician assisted suicide, 2016.

76. World Medical Association. WMA resolution on euthanasia, 2016.

77. World Medical Association. WMA declaration on euthanasia and physician-assisted suicide, 2019.

Cite this article as: Hempton C. Voluntary assisted dying in the Australian state of Victoria: an overview of challenges for clinical implementation. Ann Palliat Med 2021;10(3):35753585. doi: 10.21037/apm-20-1157 